\title{
INDEKS DMF-T DAN PERIODONTITIS PADA PASIEN DI KLINIK PERTAMEDIKA YOS SUDARSO JAKARTA UTARA
}

\author{
Pudentiana Rr RE ${ }^{1}$, Indrayati Fadjeri ${ }^{2}$, Dwi Priharti ${ }^{3}$, Mariyati ${ }^{4}$ \\ 1,2,3 Jurusan Keperawatan Gigi Poltekkes Kemenkes Jakarta I, Indonesia \\ ${ }^{4}$ Klinik Pertamedika Yos Sudarso Jakarta Utara, Indonesia
}

\begin{tabular}{ll}
\hline Info Artikel & Abstrak \\
\hline Genesis Naskah: & Latar Belakang: Masalah kesehatan gigi yang banyak diderita masyarakat Indonesia adalah \\
Submitted: 2021-01-28 & karies gigi dan penyakit periodontal. presentase penduduk yang mempunyai masalah gigi dan \\
Revised: 2021-03-03 & mulut meningkat tahun 2013 dari 25,9\% menjadi 57,6\% di tahun 2018. karies gigi tidak \\
Accepted: 2021-03-08 & ditangani maka penyakit ini dapat menyebabkan nyeri, penanggalan gigi, infeksi bahkan dapat \\
& menyebabkan penyakit periodontal contohnya periodontitis. Tujuan: Tujuan penelitian ini \\
& adalah untuk mengetahui gambaran indeks DMF-T dan periodontitis pada pasien di Klinik \\
\hline Kata Kunci: & Pertamedika Yos Sudarso Periode Bulan Januari s/d Maret tahun 2020. Metode: Penelitian ini \\
Indeks DMF-T, & menggunakan metode deskriptif dengan sampel penelitian menggunakan teknik total sampling \\
Periodontitis, Klinik & sebanyak 61 responden. Data yang digunakan yaitu data sekunder yang diambil dari rekam \\
Pertamedika Yos Sudarso & medis pasien. Hasil: Pasien Klinik Pertamedika Yos Sudarso memiliki rata-rata indeks DMF-T \\
& sebesar 6,57 termasuk kriteria tinggi. Untuk kejadian periodontitis diperoleh responden tidak \\
& mengalami periodontitis 50,8\% dan mengalami periodontitis 49,2\%. Perbandingan berdasarkan \\
& jenis kelamin diperoleh laki-laki memiliki indeks DMF-T dan kejadian periodontitis lebih tinggi \\
& daripada perempuan. Kesimpulan: Pasien Klinik Pertamedika Yos Sudarso memiliki indeks \\
& DMF-T kriteria tinggi dan mengalami periodontitis
\end{tabular}

\begin{tabular}{|c|c|}
\hline \multicolumn{2}{|c|}{ DMF-T INDEX AND PERIODONTITIS IN PATIENTS AT THE YOS SUDARSO } \\
\hline Keywords: & Abstract \\
\hline $\begin{array}{l}\text { DMF-T Index, Periodontitis } \\
\text { Incidence, Pertamedika } \\
\text { Clinic Yos Sudarso }\end{array}$ & $\begin{array}{l}\text { Background: Dental health problems suffered by many people in Indonesia are dental caries and } \\
\text { periodontal disease. the percentage of the population who have dental and mouth problems } \\
\text { increased in } 2013 \text { from } 25.9 \% \text { to } 57.6 \% \text { in } 2018 \text {. Dental caries is not treated so this disease can } \\
\text { cause pain, tooth loss, infection and even can cause periodontal disease for example } \\
\text { periodontitis. Objective: The purpose of this study was to determine the description of the DMF- } \\
\text { T index and periodontitis in patients at the Yos Sudarso Pertamedika Clinic for the period of } \\
\text { January to March } 2020 \text {. Method: This study used a descriptive method with a sample of research } \\
\text { using a total sampling technique of } 61 \text { respondent. The data used are secondary data taken from } \\
\text { the patient's medical record. Results: Pertamedika Yos Sudarso Clinic patients had an average } \\
\text { DMF-T index of } 6.57 \text { including high criteria. For the occurrence of periodontitis, respondents } \\
\text { did not have periodontitis } 50.8 \% \text { and had periodontitis } 49.2 \% \text {. Comparison based on sex } \\
\text { obtained by men having DMF-T index and periodontitis is higher than women. Conclusion: } \\
\text { Pertamedika Yos Sudarso Clinic patient has a high DMF-T index criteria and has a periodontitis } \\
\text { occurrence. }\end{array}$ \\
\hline
\end{tabular}

Korespondensi Penulis:

Mariyati

Jl. Yos Sudarso No.34, Tanjung Priok, Jakarta Utara

Email: mayrajita@yahoo.co.id 


\section{Pendahuluan}

Word Health Organization cit. Malik (2008) menyatakan kesehatan merupakan bagian terpenting dalam kehidupan manusia, sehat secara jasmani dan rohani. Kesehatan yang perlu diperhatikan selain kesehatan tubuh secara umum, juga kesehatan gigi dan mulut, karena kesehatan gigi dan mulut dapat mempengaruhi kesehatan tubuh secara menyeluruh. Dengan kata lain bahwa kesehatan gigi dan mulut merupakan bagian integral dari kesehatan tubuh secara keseluruhan yang tidak dapat dipisahkan dari kesehatan tubuh secara umum (Purnama et al., 2020).

Penyakit gigi dan mulut terutama karies dan penyakit periodontal yang sering dialami oleh usia dewasa (Kamelia, 2020). Hasil Riset Kesehatan Dasar yang dilakukan oleh Kementerian Kesehatan Republik Indonesia tahun 2013 dan 2018 menunjukkan presentase penduduk yang mempunyai masalah gigi dan mulut meningkat dari $25,9 \%$ menjadi $57,6 \%$ (Kemenkes, 2018).

Prevalensi karies cenderung meningkat seiring dengan bertambahnya umur yang berarti adanya kecenderungan penurunan status kesehatan gigi dengan meningkatnya umur. Usia dan jenis kelamin merupakan faktor yang dapat mempengaruhi angka kejadian karies gigi. Beberapa penelitian mengungkapkan bahwa prevalensi karies gigi pada wanita $(59,1 \%)$ lebih tinggi daripada laki-laki $(40,9 \%)$, penelitian lain menunjukkan perbedaan yang lebih besar antara wanita (65,5\%) dan laki-laki (34,5\%) (Sosiawan et al., 2015). Penelitian lain (Ramdiani et al., 2020) membuktikan laki-laki memiliki kondisi kesehatan gigi yang lebih baik daripada perempuan. Maka dapat artinya angka kejadian karies gigi dapat dipengaruhi oleh jenis kelamin dan usia.

Karies gigi dapat dialami oleh setiap orang dan dapat timbul pada satu permukaan atau lebih serta dapat meluas ke bagian yang lebih dalam dari gigi misalnya dari email ke dentin atau ke pulpa (Ramayanti dan Purnakarya, 2013). Keadaan mulut yang buruk menyebabkan karies gigi bahkan akan mengganggu fungsi dan aktivitas rongga mulut (Kasihani et al., 2021). Menurut Kiswaluyo (2013) apabila karies gigi tidak ditangani maka penyakit ini dapat menyebabkan nyeri, penanggalan gigi, infeksi bahkan dapat menyebabkan penyakit periodontal

(C) Jurusan Keperawatan Gigi Poltekkes Kemenkes Jakarta I Jl. Wijaya Kusuma No. 47-48 Cilandak Jakarta Selatan, Indonesia email: jdht@poltekkesjakarta1.ac.id contohnya periodontitis Di lain pihak, penyakit periodontal terjadi pada gangguan jaringan pendukung di sekitar gigi, yaitu pada jaringan periodontium (Anwar et al., 2018). Prevalensi dan intensitas kejadian penyakit periodontal di Indonesia menduduki urutan kedua yaitu sebesar 96,58\% (Ari et al., 2018).

Jaringan periodontal adalah jaringan yang mengelilingi gigi dan berfungsi sebagai penyangga gigi, terdiri dari ginggiva, sementum, jaringan ikat periodontal dan tulang alveolar. Ada dua tipe penyakit periodontal yang biasa dijumpai yaitu gingivitis dan periodontitis (Sugiarti et al., 2017). Periodontitis merupakan suatu penyakit inflamasi destruktif pada jaringan penyangga gigi yang disebabkan oleh mikroorganisme spesifik, yang menghasilkan kerusakan lanjut ligamen periodontal dan tulang alveolar dengan terbentuknya poket, resesi gingiva, maupun keduanya (Kodir et al., 2014). Tanda-tanda klinis dari periodontitis adalah adanya inflamasi gingiva, pembengkakan papila interdental, kerusakan tepi gingiva, terbentuknya pocket/saku gingiva dan resesi gingiva (Wiyantini et al, 2014).

Periodontitis hampir diderita oleh manusia di seluruh dunia dan prevalensinya mencapai $50 \%$ dari jumlah populasi dewasa. Berdasarkan Riset Kesehatan Dasar (2018), prevalensi nasional periodontitis pada kelompok umur 35-44 tahun adalah 77\%, diantaranya $68,9 \%$ tidak dilakukan perawatan. Periodontitis yang ditidak dirawat dapat menyebabkan gigi goyang dan mudah tanggal (Susilawati, 2015).

Anwar et al. (2018) menyatakan ada hubungan positif antara mikrobiologis penyebab karies dan penyakit periodontal. Sesuai hasil penelitian Wangsarahardja (2005) bahwa kondisi gigi geligi yang buruk mempunyai risiko 1,3 kali lebih besar untuk mengalami penyakit periodontal dibanding dengan individu yang mempunyai kesehatan gigi yang baik.

Klinik Pertamedika Yos Sudarso adalah salah satu poliklinik yang memberikan pelayanan kesehatan umum dan kesehatan gigi serta merupakan satelit dari Rumah Sakit Pertamina Jaya yang melayani pasien umum, asuransi dan BPJS. Kebanyakan pasien bersasal dari karyawan Pertamina. Berdasarkan data laporan penyakit yang ada di klinik gigi gigi bulan Januari 2020 menunjukkan tiga penyakit gigi tertinggi 
diantaranya karies dentin, pulpitis dan kelainan jaringan periodontal.

\section{Metode}

Desain penelitian yang digunakan adalah penelitian secara deskriptif. Populasi dalam penelitian ini adalah seluruh pasien di Klinik Pertamedika Yos Sudarso periode bulan Januari s/d Maret tahun 2020. Teknik pengambilan sampel menggunakan total sampling sebanyak 61 orang.

Jenis data yang digunakan digunakan dalam penelitian ini adalah data sekunder, yaitu data mengenai perawatan gigi pada pasien yang tercatat di rekam medis klinik Pertamedika Yos Sudarso bulan Januari s/d Maret tahun 2020. Instrumen yang digunakan adalah lembar rekapitulasi data. Penelitian ini diolah dan dianalisa dalam program excel dan disajikan dalam bentuk distribusi frekuensi.

\section{Hasil}

Tabel 1. Distribusi frekuensi karakteristik responden berdasarkan jenis kelamin

\begin{tabular}{cccc}
\hline No & $\begin{array}{c}\text { Jenis } \\
\text { Kelamin }\end{array}$ & $\begin{array}{c}\text { Jumlah } \\
\text { Responden }\end{array}$ & $\begin{array}{c}\text { Persentase } \\
(\boldsymbol{\%})\end{array}$ \\
\hline 1 & Laki-laki & 46 & 75,4 \\
2 & Perempuan & 15 & 24,6 \\
\hline & Jumlah & 61 & 100 \\
\hline
\end{tabular}

Tabel 1 menunjukkan bahwa responden laki-laki sebanyak 9 orang (30\%), umur 21 - 25 tahun sebanyak 46 orang $(75,4 \%)$ sedangkan perempuan 15 orang $(24,6 \%)$.

Tabel 2. Gambaran Rata-rata Indek DMF-T

\begin{tabular}{ccccc}
\hline \multirow{2}{*}{$\begin{array}{c}\text { Responden } \\
\text { (orang) }\end{array}$} & \multicolumn{3}{c}{ Komponen DMF-T } & Indek \\
\cline { 2 - 4 } & Decay & Missing & Filling & DMF-T \\
\hline 61 & 162 & 137 & 112 & 401 \\
\hline Rata-rata & 2,66 & 2,25 & 1,84 & 6,57 \\
\hline
\end{tabular}

Tabel 2 menunjukkan bahwa dari 61 responden didapatkan skor DMF-T sebesar 401 dan DMF-T ratarata sebesar 6,57 dengan skor $\mathrm{D}=2,66 \mathrm{M}=2,25 \mathrm{~F}=$ 1,84. Hal ini dapat diartikan bahwa setiap orang yang diperiksa memiliki pengalaman karies gigi sebanyak 6-7 gigi tiap responden. Selanjutnya berdasarkan

(C) Jurusan Keperawatan Gigi Poltekkes Kemenkes Jakarta I Jl. Wijaya Kusuma No. 47-48 Cilandak Jakarta Selatan, Indonesia email: jdht@poltekkesjakarta1.ac.id pengelompokkan sesuai kriteria DMF-T menurut target WHO.

Tabel 2. Distribusi frekuensi kriteria indek DMF-T

\begin{tabular}{clcc}
\hline No & Status Karies & $\begin{array}{c}\text { Jumlah } \\
\text { Responden }\end{array}$ & $\begin{array}{c}\text { Persentase } \\
(\%)\end{array}$ \\
\hline 1 & Sangat Rendah & 3 & 4,9 \\
2 & Rendah & 5 & 8,2 \\
3 & Sedang & 14 & 23 \\
4 & Tinggi & 13 & 21,3 \\
5 & Sangat Tinggi & 26 & 42,6 \\
\hline & Jumlah & 61 & 100 \\
\hline
\end{tabular}

Tabel 2 menunjukkan bahwa responden yang mempunyai indeks DMF-T kriteria sangat rendah sebanyak 3 orang (4,9\%), kriteria rendah sebanyak 5 orang $(8,2 \%)$, kriteria sedang sebanyak 14 orang (23\%), kriteria tinggi sebanyak 13 orang $(21,3 \%)$ dan kriteria sangat tinggi sebanyak 26 orang $(42,6 \%)$.

Tabel 3. Distribusi frekuensi Periodontitis

\begin{tabular}{cccc}
\hline No & Periodontitis & $\begin{array}{c}\text { Jumlah } \\
\text { Responden }\end{array}$ & $\begin{array}{c}\text { Persentase } \\
(\boldsymbol{\%})\end{array}$ \\
\hline 1 & Ya & 30 & 49,2 \\
2 & Tidak & 31 & 50,8 \\
\hline & Jumlah & 61 & 100 \\
\hline
\end{tabular}

Tabel 3 menunjukkan bahwa responden yang memiliki periodontitis sebanyak 30 orang $(49,2 \%)$ dan responden yang tidak memiliki periodontitis sebanyak 31 orang $(50,8 \%)$.

Tabel 4. Distribusi frekuensi Indek DMF-T berdasarkan jenis kelamin

\begin{tabular}{cccc}
\hline \multirow{2}{*}{ Indek DMF-T } & \multicolumn{2}{c}{ Jenis kelamin } & Jumlah \\
\cline { 2 - 4 } & Laki-laki & Perempuan & \\
\hline Sangat rendah & 2 & 1 & 3 \\
Rendah & 5 & 0 & 5 \\
Sedang & 12 & 2 & 14 \\
Tinggi & 10 & 3 & 13 \\
Sangat tinggi & 17 & 9 & 26 \\
\hline Jumlah & 46 & 15 & 61 \\
\hline
\end{tabular}

Tabel 4 menunjukan bahwa responden laki-laki yang memiliki karies sangat rendah sebanyak 2 orang dan responden perempuan yang memiliki karies sangat rendah sebanyak 1 orang, responden laki-laki yang memiliki karies rendah sebanyak 5 orang dan tidak

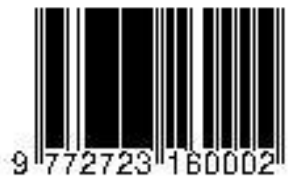


terdapat responden perempuan yang memiliki karies rendah, responden laki-laki yang memiliki karies sedang sebanyak 12 orang dan responden perempuan yang memiliki karies sedang sebanyak 2 orang, responden laki-laki yang memiliki karies tinggi sebanyak 10 orang dan responden perempuan yang memiliki karies tinggi sebanyak 3 orang sedangkan responden laki-laki memiliki karies sangat tinggi sebanyak 17 orang dan responden perempuan yang memiliki karies sangat tinggi sebanyak 9 orang.

Tabel 5. Distribusi frekuensi Periodontitis berdasarkan jenis kelamin

\begin{tabular}{ccc}
\hline \multirow{2}{*}{ Periodontitis } & \multicolumn{2}{c}{ Jenis kelamin } \\
\cline { 2 - 3 } & Laki-laki & Perempuan \\
\hline Ya & 22 & 9 \\
Tidak & 24 & 6 \\
\hline Jumlah & 26 & 17 \\
\hline
\end{tabular}

Tabel 5 menunjukan bahwa responden laki-laki yang memiliki periodontitis sebanyak 22 orang dan perempuan yang memiliki periodontitis sebanyak 9 orang sedangkan responden laki-laki yang tidak memiliki periodontitis sebanyak 24 orang dan perempuan yang tidak memiliki periodontitis sebanyak 6 orang.

\section{Pembahasan}

Hasil penelitian diperoleh dari 61 responden didapatkan bahwa komponen Decay sebesar 2,66, sedangkan komponen Missing sebesar 2,25 dan komponen Filling sebesar 1,84 sehingga penjumlahan indek DMF-T sebesar 6,57 artinya hasil tersebut dapat termasuk kriteria tinggi. Hasil diatas tidak jauh berbeda bila dibandingkan dengan hasil penelitian Tjahja dan Ghani (2010) pada Puskesmas di Provinsi DKI Jakarta, didapatkan tingkat keparahan karies gigi pada pengunjung Puskesmas dengan nilai DMF-T $>6$, artinya pengunjung Puskesmas di DKI Jakarta mempunyai riwayat gigi berlubang 6 gigi per orang. Tingginya karies gigi disebabkan adanya endapan plak yang mudah melekat pada gigi (Sosiawan et al., 2015). Hal ini diperkuat pendapat (Tarigan, 2013) plak yang merupakan salah satu penyebab utama terjadinya karies dapat mempengaruhi rendah tidaknya tingkat status kebersihan gigi seseorang. Jadi apabila dapat selalu menjaga tingkat kebersihan gigi dapat mencegah berbagai penyakit gigi.

Hasil penelitian gambaran kejadian periodontitis diperoleh responden yang memiliki periodontitis sebanyak 30 orang $(49,2 \%)$ dan responden yang tidak memiliki periodontitis sebanyak 31 orang $(50,8 \%)$. Hal ini diakibatkan karies gigi responden yang tidak dirawat, terlihat dari data indeks karies gigi menunjukkan sebagain besar responden memiliki ratarata DMF-T sebesar 6,57. Karies merupakan masalah gigi dan mulut yang menyebabkan tingginya persentase pencabutan gigi. Karies adalah masalah yang sering dipengaruhi oleh kebiasaan makan, status nutrisi dan kesehatan rongga mulut (Rosidah et al., 2020). Sejalan juga dengan pendapat (Ramayanti dan Purnakarya, 2013) karies gigi dapat dialami oleh setiap orang dan dapat timbul pada satu permukaan atau lebih serta dapat meluas ke bagian yang lebih dalam dari gigi misalnya dari email ke dentin atau ke pulpa. Diperkuat (Kiswaluyo, 2013) menyatakan apabila karies gigi tidak ditangani maka penyakit ini dapat menyebabkan nyeri, penanggalan gigi, infeksi bahkan dapat menyebabkan penyakit periodontal contohnya periodontitis. Bahkan karies gigi dapat mengganggu sistem pengunyahan dan mengganggu sistem pencernaan sehingga dapat mempengaruhi kulaitas hidup (Purnama et al., 2020).

Hasil penelitian gambaran indeks DMF-T berdasarkan jenis kelamin menunjukkan bahwa responden laki-laki memiliki pengalaman karies sebanyak 46 orang $(75,4 \%)$ sedangkan perempuan hanya 15 orang $(25,6 \%)$ Hal ini bila dibandingkan penelitian (Notohartojo et al., 2011) diperoleh perempuan yang memiliki nilai DMF-T sebesar 44,6\% sedangkan laki-laki sebesar 55,4\%, artinya penelitian yang dilakukan di Klilik Pertamedika Yosudarso responden laki-laki memiliki indek karies gigi yang lebih tinggi. Hal ini disebabkan karena sebagain besar pasien di Klinik Pertamedika Yosudarso adalah pekerja kapal dimana kegiatan sehari-harinya adalah di laut, sehingga sering konsumsi air laut yang kadar garam yang tinggi dan dapat menyebabkan karies gigi. Diperkuat (Sukmana, 2016) menyatakan air garam mempunyai pengaruh terhadap kelangsungan bakteri khususnya bakteri utama penyebab karies gigi yaitu Streptococcus mutans. 
Hasil penelitian gambaran kejadian periodontitis berdasarkan jenis kelamin menunjukkan bahwa responden laki-laki lebih banyak memiliki kasus periodontitis dibandingkan dengan perempuan. Hasil tersebut berbeda dengan penelitian (Wiyantini et al., 2014) menunjukkan bahwa prosentase terbanyak pada responden penderita periodontitis adalah jenis kelamin perempuan. Hal ini dikarenakan responden laki-laki kurang bisa menjaga kebersihan gigi dan mulutnya. Sesuai hasil penelitian (Wangsarahardja, 2005) bahwa kondisi gigi geligi yang buruk mempunyai risiko 1,3 kali lebih besar untuk mengalami penyakit periodontal dibanding dengan individu yang mempunyai kesehatan gigi yang baik. Selain itu faktor yang mempengaruhi tidak selajan dengan penelitian (Wiyantini et al., 2014) dikarenakan jumlah responden laki-laki dalam penelitian ini lebih banyak daripada perempuan, terlihat dari persentasi laki-laki sebesar $75,4 \%$ sedangkan perempuan $24,6 \%$.

\section{Kesimpulan dan Saran}

Berdasarkan hasil penelitian, dapat disimpulkan bahwa:

1. Didapatkan rata-rata indeks DMF-T sebesar 6,57 termasuk kriteria tinggi

2. Didapatkan sebagaian besar responden tidak memiliki periodontitis $50,8 \%$ dan memiliki periodontitis $49,2 \%$

3. Laki-laki memiliki indeks DMF-T lebih tinggi daripada perempuan

4. Laki-laki memiliki kejadian periodontitis lebih banyak daripada perempuan

Sehubungan dengan hasil penelitian maka dapat disarankan sebagai berikut:

1. Memberikan masukan kepada Klinik Pertamedika Yos Sudarso untuk mengadakan program promotif dan preventif secara terprogram.

2. Memberikan masukan kepada pasien yang mengalami gigi berlubang (karies) atau periodontitis agar segera dilakukan perawatan gigi.

3. Untuk peneliti lain diharapkan dapat dilakukan penelitian dengan variabel yang berbeda dan dengan model pendekatan yang berbeda.

\section{Daftar Pustaka}

Anwar, A. I., Adnan, A. P., Ayub, A. A. (2018).
Hubungan Antara Status Periodontal Dan Status Gigi Geligi Usia Dewasa Masyarakat Kelurahan Malino Kabupaten Gowa. Cakradonya Dental Journal, 10(2), 71-77.

Ari, I. D., Kamelia, E., Miko, H. (2018). Pengaruh Berkumur Larutan Madu Terhadap Gingivitis pada Siswa Kelas VIII MTSN 3 Kota Tasikmalaya. Actual Research Science Academic, 3(2), 1-9.

Kamelia, E. (2020). Gambaran Kebiasaan Makan Makanan Kariogenik dan Kerusakan Gigi Geraham Tetap Pertama. Jurnal Ilmiah Keperawatan Gigi, 1(1).

Kasihani, N. N., Ngatemi, Purnama, T. (2021). Determinants of Parental Behavior in Maintaining Deciduous Teeth in Early Childhood: A Cross Sectional Study. European Journal of Molecular \& Clinical Medicine, $8(02)$.

Kemenkes, R. I. (2018). Hasil Utama Riset Kesehatan Dasar Tahun 2018. Kementrian Kesehatan Republik Indonesia, 1-100.

Kiswaluyo, K. (2013). Perawatan Periodontitis pada Puskesmas Sumbersari, Puskesmas Wuluhan dan RS Bondowoso. Stomatognatic-Jurnal Kedokteran Gigi, 10(3), 115-120.

Kodir, A. I. A., Herawati, D., Murdiastuti, K. (2014). Perbedaan Efektivitas Antara Pemberian Secara Sistemik Ciprofloksasin dan Amoksisilin Setelah Scaling \& Root Planing Pada Periodontitis Kronis Penderita Hipertensi. Jurnal Kedokteran Gigi, 5(4), 323-328.

Malik, A. (2008). Kesehatan Gigi dan Mulut: Laporan kesehatan Badan Pengembangan Sistem Informasi dan Telematika Daerah (Bapesitelda) Provinsi Jawa Barat. Departemen Ortodonti Universitas Padjajaran: Bandung.

Notohartojo, I. T., Suratri, M. A. L., Riyadina, W., Nainggolan, O. (2011). Nilai Karies Gigi pada Karyawan Kawasan Industri di Pulo Gadung Jakarta. Media Penelitian Dan Pengembangan Kesehatan, 21(4).

Purnama, T., Fadjeri, I., Widiyastuti, R. (2020). Model Mentoring Teachers and Parents as an Efforts for Brushing Teeth Behavior in Preschool Children. Indian Journal of Forensic Medicine \& Toxicology, 14(4), 3511-3516.

Purnama, T., Ngatemi, N., Sofian, R., Kasihani, N. N., RE, P. R., Nurbayani, S. (2020). Model 5 Days Gosgi Sebagai Upaya Pembentukan Kemandirian Menggosok Gigi Anak Usia Dini di Sekolah. Quality: Jurnal Kesehatan, 14(1), 19 24. 
Ramayanti, S., \& Purnakarya, I. (2013). Peran makanan terhadap kejadian karies gigi. Jurnal Kesehatan Masyarakat Andalas, 7(2), 89-93.

Ramdiani, D., Yulita, I., Sasongko, B. G., Purnama, T. (2020). Required Treatment Index (RTI) Pada Pasien Dewasa di Klinik Dokter Gigi Tjang Riyanto Cahyadi Kota Bogor. JDHT Journal of Dental Hygiene and Therapy, 1(2), 55-60.

Rosidah, N. E., Nurbayani, S., Barus, A., Sofian, R., Purnama, T. (2020). Kebutuhan Perawatan Gigi Dan Mulut Pada Pasien Lansia di Poliklinik Pertamedika Bekasi Periode Januari-Maret Tahun 2020. JDHT Journal of Dental Hygiene and Therapy, 1(1), 1-5.

Sosiawan, A., Heroesoebekti, R., Hapsoro, A., Santosa, L. M. (2015). Gambaran Tingkat Keparahan Karies Gigi Pada Ibu-ibu Usia 36-45 Tahun Dusun Claket Desa Claket Kecamatan Pacet Kabupaten Mojokerto Pada Bulan April 2016. Dental Public Health Journal, 6(2), 1-12.

Sugiarti, T., Santik, Y. D. P. (2017). Kejadian periodontitis di Kabupaten Magelang. HIGEIA (Journal of Public Health Research and Development), 1(4), 97-108.

Sukmana, B. I. (2016). Gambaran karies dengan menggunakan DMF-T pada masyarakat pesisir pantai Kelurahan Takisung Kecamatan Takisung Kabupaten Tanah Laut. Dentino: Jurnal Kedokteran Gigi, 1(2), 75-78.

Susilawati, I. D. A. (2015). Periodontal infection is a "Silent Killer." Stomatognatic-Jurnal Kedokteran Gigi, 8(1), 21-26.

Tarigan, R. (2013). Karies gigi. Jakarta: EGC.

Tjahja, I., Ghani, L. (2010). Status Kebersihan Gigi dan Mulut Ditinjau dari Faktor Individu Pengunjung Puskesmas DKI Jakarta Tahun 2007. Buletin Penelitian Kesehatan, 38(2), 52-66.

Wangsarahardja, K. (2005). Penyakit periodontal sebagai faktor risiko penyakit jantung koroner. Universa Medicina, 24(3), 136.

Wiyantini, T., Setyawan, H., Hadisaputro, S. (2014). Faktor-faktor Lokal dalam Mulut dan Perilaku Pencegahan yang Berhubungan dengan Periodontitis. Case Study at Three Primary Health Care in Demak. 